\title{
Effect of Mn Content on Microstructure and Cryogenic Mechanical Properties of a $7 \%$ Ni Steel
}

\author{
Hong-Wei Cao ${ }^{1,2} \cdot$ Xing-Hong Luo ${ }^{2} \cdot$ Guo-Feng Zhan ${ }^{3} \cdot$ Shi Liu ${ }^{2}$
}

Received: 29 September 2017 / Revised: 28 November 2017/Published online: 25 January 2018

(C) The Chinese Society for Metals and Springer-Verlag GmbH Germany, part of Springer Nature 2018

\begin{abstract}
The effect of Mn content on the microstructure and cryogenic mechanical properties of a 7\% Ni steel was investigated within the Mn content range from $0.13 \%$ to $0.36 \%$. The microstructure of the steel as determined by optical microscopy, scanning electron microscopy, transmission electron microscopy, electron backscattering diffraction and X-ray diffraction was presented, and the low-temperature mechanical properties were given. The size of prior austenite grain did not change a lot as Mn content increased. Film-like reversed austenite, having high stability, was found mainly in the specimens with lower Mn content; however, in the specimen with the highest Mn content, the role of Mn was not obvious in stabilizing reversed austenite. Besides, with increasing Mn content, the amount of reversed austenite at grain boundaries gradually decreased. The variable Mn content had a significant effect on cryogenic toughness, but not apparent on cryogenic tensile strength or yield strength. An excellent combination of cryogenic tensile and impact properties was obtained when $\mathrm{Mn}$ content of steel was $0.13 \%$.
\end{abstract}

Keywords 7\% Ni steel $\cdot$ Mn content $\cdot$ Microstructure $\cdot$ Reversed austenite $\cdot$ Cryogenic mechanical properties

\section{Introduction}

Low-temperature steels for liquefied natural gas (LNG) projects have been attracting more and more attentions due to the high global demand of LNG. As a mature steel with excellent cryogenic mechanical properties, $9 \% \mathrm{Ni}$ steel has been generally used in LNG projects for the past couple of decades [1, 2]. However, as one of valuable metal resources, nickel price is high and would be higher in future, which lead to a high cost of $9 \% \mathrm{Ni}$ steel. Therefore, it is of great interests to develop nickel saving cryogenic steels, which have similar mechanical properties, especially

Available online at http://link.springer.com/journal/40195

Xing-Hong Luo

xhluo@imr.ac.cn

1 School of Materials Science and Engineering, University of Science and Technology of China, Shenyang 110016, China

2 CAS Key Laboratory of Nuclear Materials and Safety Assessment, Institute of Metal Research, Chinese Academy of Sciences, Shenyang 110016, China

3 Research and Development Center of Wuhan Iron and Steel (Group) Corp, Wuhan 430080, China cryogenic toughness, to $9 \% \mathrm{Ni}$ steel. Recent research indicates that upon proper alloy design and processing, $7 \%$ $\mathrm{Ni}$ steel could be a good substitute for $9 \% \mathrm{Ni}$ steel used in LNG projects [3].

$\mathrm{Mn}$ is an important alloy element, which has various influences on both microstructure and mechanical properties of steels. For example, Mn is beneficial to restraining grain growth due to its enrichment in cementite particles. When Mn content is high, these particles can be fine enough to pin grain boundaries during heat treatment [4]. Besides, Mn content may also determine mechanical properties by affecting constitution of phases [5-7]. However, less attention has been paid so far to the effects of $\mathrm{Mn}$ and its content on microstructure and cryogenic properties of nickel steels. Generally, as Ni content in steel decreased by about $2 \%$, it could be taken for granted to increase $\mathrm{Mn}$ content to compensate the potential loss of mechanical properties caused by nickel saving. But unexpectedly, in our primary research, good cryogenic mechanical properties, although not excellent enough, were obtained in a 7\% $\mathrm{Ni}$ steel with relatively low content of $\mathrm{Mn}$. This result indicates that it is low level, rather than high level, of $\mathrm{Mn}$ content that would be beneficial to cryogenic mechanical properties of the $7 \% \mathrm{Ni}$ steel, but the mechanism keeps 
unclear. Therefore, this study takes aim at identifying the influence of low content of $\mathrm{Mn}$ on the microstructure, especially formation of reversed austenite, and cryogenic mechanical properties of a $7 \% \mathrm{Ni}$ steel.

\section{Experimental Material and Procedure}

The $7 \% \mathrm{Ni}$ steels, containing about $0.04 \% \mathrm{C}, 7.3 \% \mathrm{Ni}$, a few $\mathrm{Si}$, and three different contents of $\mathrm{Mn}, 0.13 \%$ (Steel A), $0.21 \%$ (Steel B) and $0.36 \%$ (Steel C), were prepared. The steels were hot rolled to final thickness of $15-\mathrm{mm}$ sheets and then cut into plates of $15 \mathrm{~mm} \times 60 \mathrm{~mm} \times 90 \mathrm{~mm}$.

QLT treatment, which consists of quenching, intercritical quenching and tempering, was employed in this study. Specifically, all plates were quenched after heating at $830{ }^{\circ} \mathrm{C}$ for $1 \mathrm{~h}$, then intercritically quenched after heating at $690{ }^{\circ} \mathrm{C}$ for $1 \mathrm{~h}$ and finally tempered at $580{ }^{\circ} \mathrm{C}$ for $1 \mathrm{~h}$.

Standard round tensile specimens with a gauge diameter of $5 \mathrm{~mm}$ and V-Notch Charpy impact samples with size of $10 \mathrm{~mm} \times 10 \mathrm{~mm} \times 55 \mathrm{~mm}$ were machined from the treated plates. Tensile tests and impact tests were conducted at $-196{ }^{\circ} \mathrm{C}$ (liquid nitrogen temperature), with three specimens for each process.

To observe prior austenite grains and microstructure with a Zeiss optical microscope (OM) and a JSM-6301F scanning electron microscope (SEM), the specimens were mechanically grounded and polished, then etched in $4 \%$ natal and saturated water solution of picric acid, respectively. The grain size was averaged from several hundreds of grains selected randomly from OM images. The fracture surface topography of selected impact specimens was observed using an SSX-550 SEM. The specimens with different contents of $\mathrm{Mn}$ were mechanically ground to $50 \mu \mathrm{m}$ and chemically thinned by twin-jet polishing at $-20{ }^{\circ} \mathrm{C}$, using a solution of $5 \%$ perchloric acid and $95 \%$ ethanol as electrolyte. The thin foils were characterized using a JEM-2100F TEM to observe morphology of reversed austenite and other microstructure.

The $\mathrm{Fe}-\mathrm{Mn}-\mathrm{Ni}$ system at $690{ }^{\circ} \mathrm{C}$ was calculated using Thermo-Calc software. The volume fractions of reversed austenite in each heat treated specimens before and after cryogenic impact tests were determined by X-ray diffraction (XRD) via comparing integrated peak intensities of $(200)_{\alpha},(211)_{\alpha},(200)_{\gamma}$ and $(220)_{\gamma}$.

The distribution of reversed austenite was determined by electron backscattering diffraction (EBSD). The specimens for EBSD were electrolytically polished with a solution of $10 \%$ perchloric acid and $90 \%$ ethanol, and the EBSD maps were scanned at a step size of $100 \mathrm{~nm}$.

\section{Results and Discussion}

\subsection{Effect of Mn Content on Microstructure}

Figure 1 shows the OM and SEM micrographs of the specimens with different $\mathrm{Mn}$ contents. It can be seen that after QLT treatment, the microstructure shows typical tempering martensite features, lath martensite structures within prior austenite grains. The prior austenite grain boundaries are clearly revealed in Fig. 1a, c and e and the lath martensite can be obviously observed in Fig. 1 b, d and $\mathrm{f}$. The variation of average grain sizes with Mn content of the three steels is shown in Fig. 2. There were no significant changes in grain sizes as Mn contents increased from $0.13 \%$ to $0.36 \%$, but prior austenite was to be subdivided into more pieces by martensite laths as Mn content increased. It is known that increase in Mn content may lead to a decrease in average grain size; however, due to the low level of Mn content of experiment steels in this work, the average grain size did not change a lot. When the Mn content is $0.13 \%$ (Steel A), the grain sizes of prior austenite are more homogeneous, which is beneficial to mechanical properties.

\subsection{Effect of Mn Content on Reversed Austenite}

It has been widely accepted that reversed austenite plays a key role in improvement of toughness of steels, especially nickel steels for cryogenic services [8-11]. The detailed microstructure of reversed austenite in the three steels was examined by TEM as presented in Fig. 3. It can be seen that the reversed austenite precipitated mainly at lath boundaries and the morphologies of the reversed austenite are different in various steels. In Steel A and B, some filmlike reversed austenite appeared in the field of view, while in Steel C, mainly blocky ones were observed. In general, film-like reversed austenite can be more rigid and stable than blocky ones because of its higher carbon content, and thus, shear transformation in the films will be more difficult [12-14]. Consequently, a stronger driving force would be needed for stable film-like reversed austenite to transform to martensite; in other words, more energy will be absorbed by film-like ones through martensite transformation, which is beneficial to restrain crack propagation and increase toughness of steel.

Energy dispersive spectrometer (EDS) was used to determine the $\mathrm{Ni}$ and $\mathrm{Mn}$ contents in the reversed austenite in Steel A, B and C, and the results are shown in Fig. 4. When Mn content increased from $0.13 \%$ to $0.36 \%$, the $\mathrm{Ni}$ content in the reversed austenite increased at first, reaching a peak value in Steel B, and then slightly decreased in Steel C. On the other hand, the Mn content in the reversed 

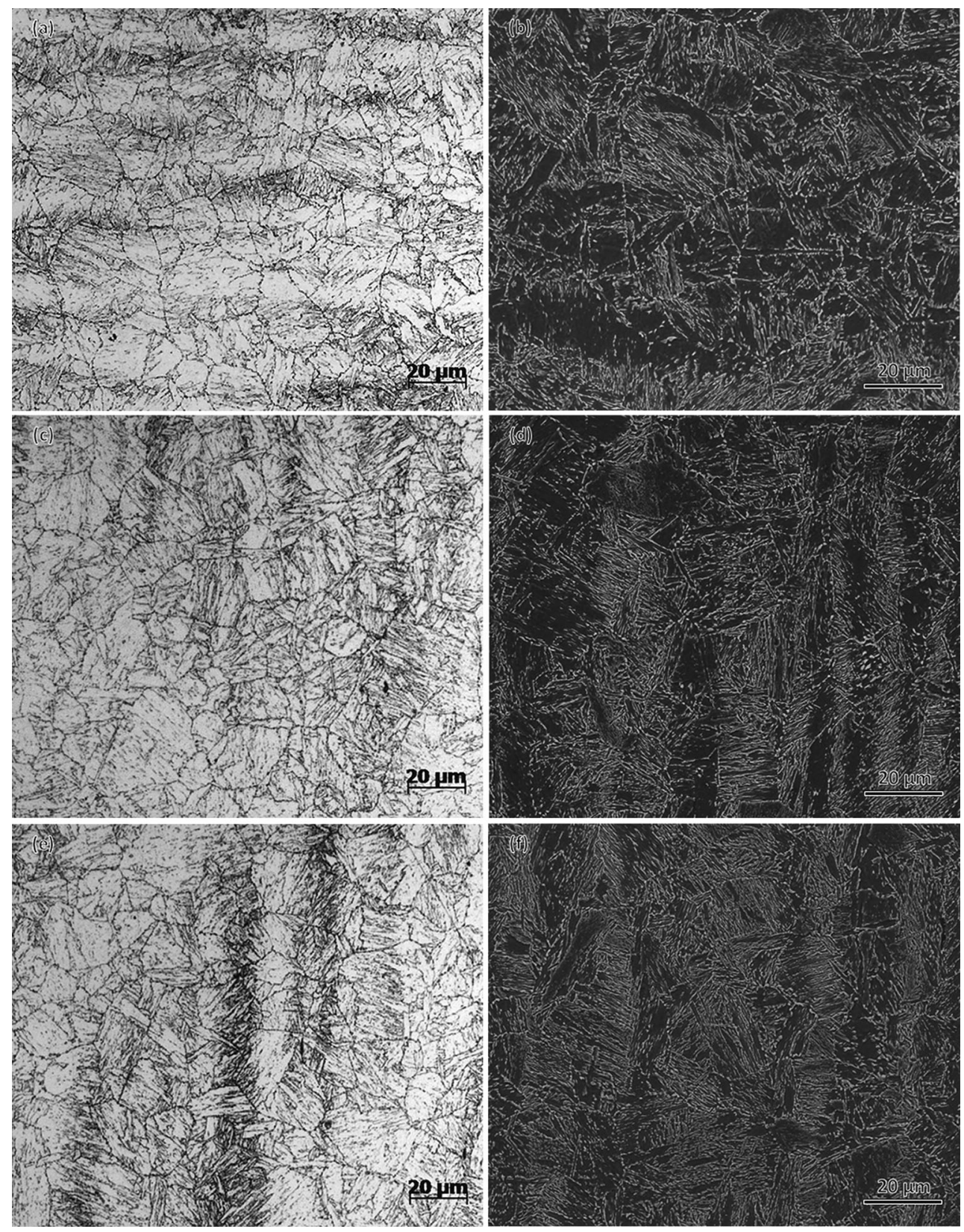

Fig. 1 Microstructure of specimens containing different Mn contents: a, b $0.13 \% \mathrm{Mn}, \mathbf{c}, \mathbf{d} 0.21 \% \mathrm{Mn}$, e, f $0.36 \% \mathrm{Mn}$

austenite increased continuously. In addition, it also can be seen that solutes $\mathrm{Ni}$ and $\mathrm{Mn}$ have been enriched in the reversed austenite during heat treatment. These elements stabilize the austenite phase and are fairly responsible for the stability of reversed austenite at low temperature [15-18]. Both $\mathrm{Ni}$ and $\mathrm{Mn}$ exist in reversed austenite as solute atoms by the replacement of $\mathrm{Fe}$ atoms, but the amount of available replacement positions is limited. Once $\mathrm{Mn}$ atoms occupy more available positions in reversed austenite as its content increased, opportunities for $\mathrm{Ni}$ atoms would be reduced. To prove it, by use of Thermo-
Calc software, the $\mathrm{Fe}-\mathrm{Mn}-\mathrm{Ni}$ system at $690{ }^{\circ} \mathrm{C}$ was calculated and the result is shown in Fig. 5. It can be seen that in austenite, the increase in Mn content invoke a decrease in $\mathrm{Ni}$ content as indicted by the arrow. Hence, the $\mathrm{Ni}$ content in the reversed austenite presented a downtrend when Mn content was higher.

The volume fractions of the reversed austenite in different specimens were characterized by XRD at room temperature before and after immersion in liquid nitrogen, and the results are shown in Fig. 6. Before the cryogenic treatment, the volume fraction of the reversed austenite 


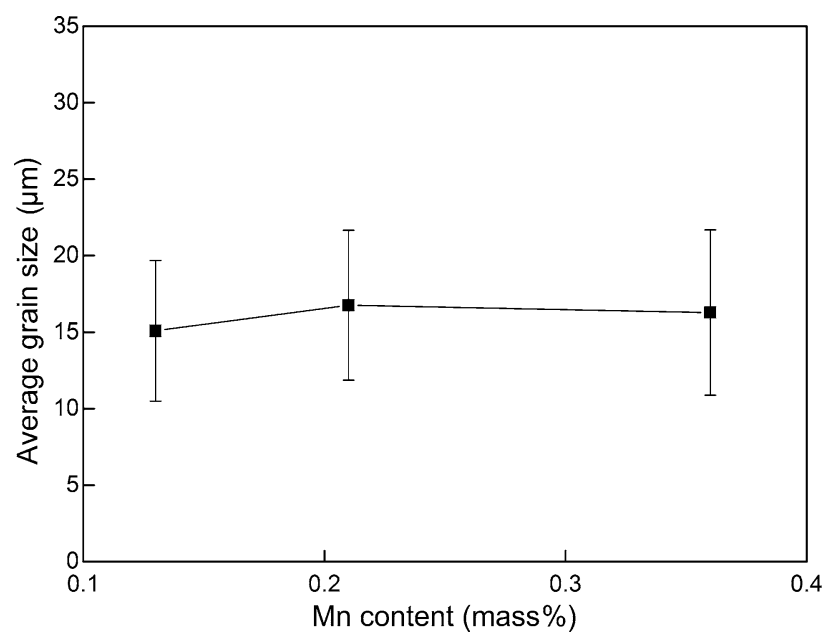

Fig. 2 Effect of Mn content on grain size of prior austenite

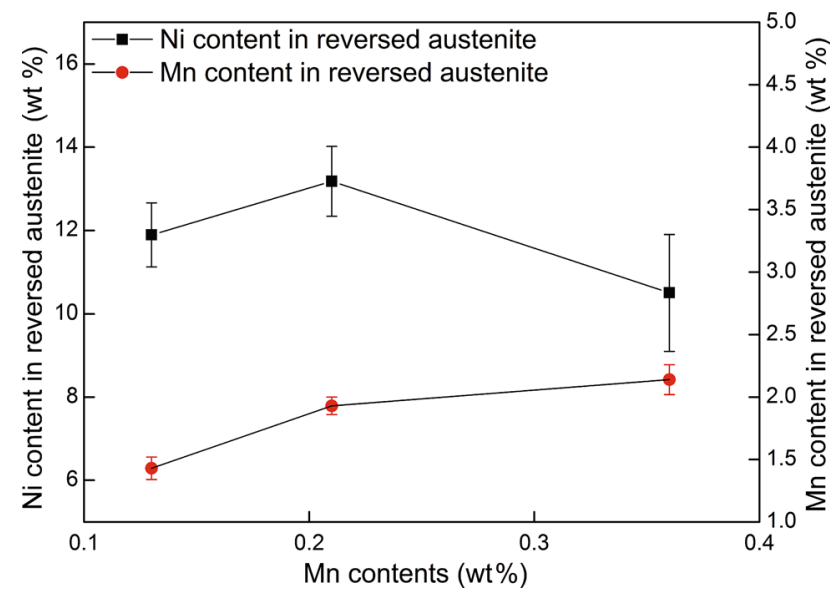

Fig. 4 Variations of $\mathrm{Ni}$ and $\mathrm{Mn}$ contents in reversed austenite as a function of Mn contents
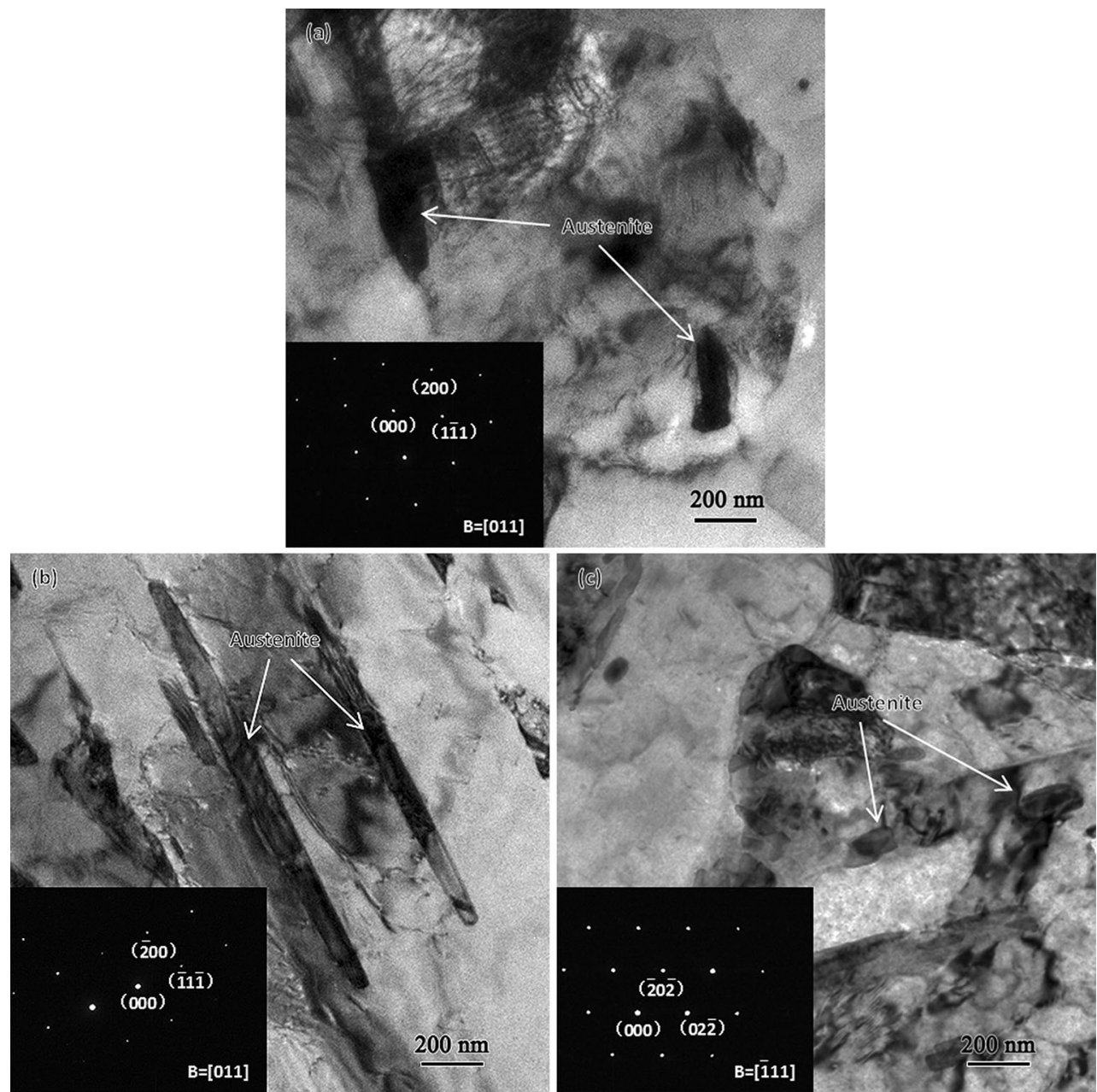

Fig. 3 TEM micrographs of specimens containing different Mn contents: a $0.13 \% \mathrm{Mn}, \mathbf{b} 0.21 \% \mathrm{Mn}$, c $0.36 \% \mathrm{Mn}$

showed an obvious uptrend as Mn content increased from $0.13 \%$ to $0.36 \%$. However, after the cryogenic treatment, the volume fractions of the reversed austenite were reduced in all specimens and the uptrend was halted when $\mathrm{Mn}$ content was beyond $0.21 \%$, which implies that, during the cryogenic treatment, some reversed austenite with lower 


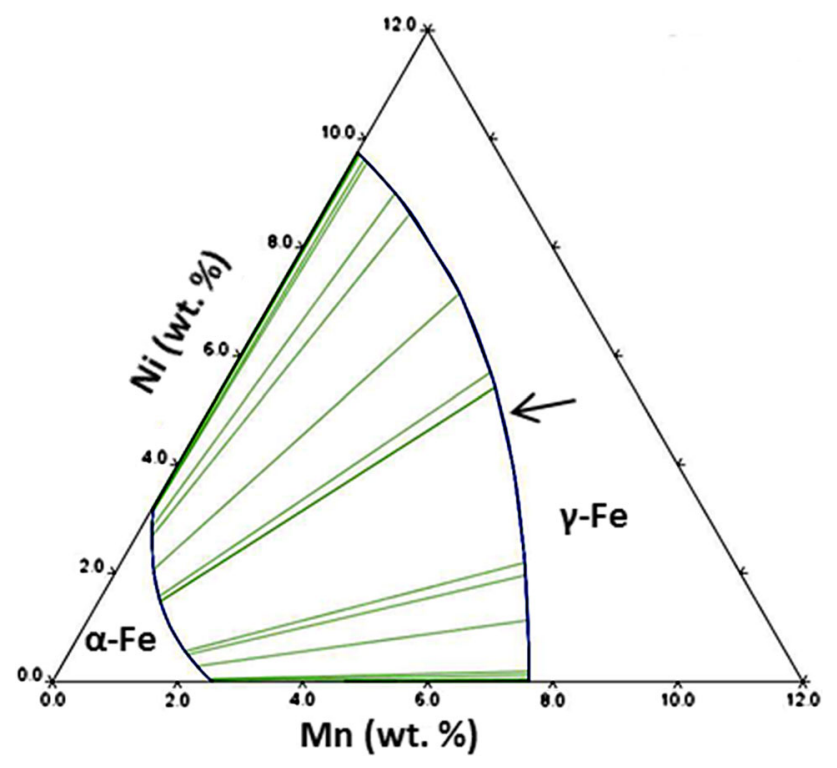

Fig. 5 Calculated isothermal section of the $\mathrm{Fe}-\mathrm{Mn}-\mathrm{Ni}$ system at $690{ }^{\circ} \mathrm{C}$

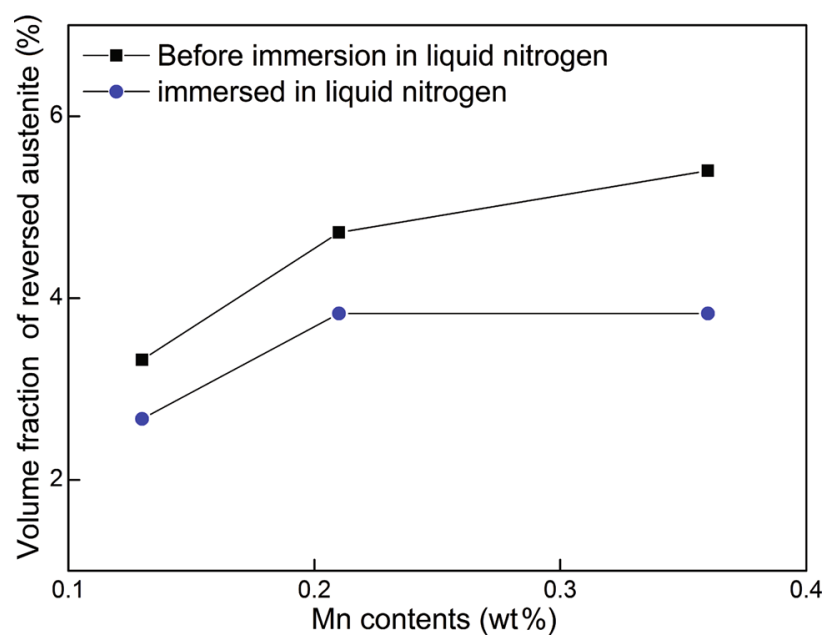

Fig. 6 Variations of volume fraction of reversed austenite with Mn contents

stability could transform to untempered martensite. Comparing the volume fractions of the reversed austenite before and after cryogenic treatment, the amount of unstable reversed austenite was higher in Steel C, i.e., the stability of the reversed austenite has been reduced with increasing $\mathrm{Mn}$ content. As shown in Fig. 4, the Ni content in the reversed austenite decreased when Mn content of the steel increased to $0.36 \%$. Obviously, there is a difference between $\mathrm{Ni}$ and $\mathrm{Mn}$ in their ability to stabilize reversed austenite. Despite higher Mn content in reversed austenite, the decrease in $\mathrm{Ni}$ content may have a stronger effect on reducing the stability. Besides, Raghavan [19] found that Mn might have a destabilizing effect on reversed austenite when its content was beyond a certain degree, which is consistent with our observation.

Figure 7 shows EBSD analysis results of the reversed austenite distribution in specimens with different $\mathrm{Mn}$ contents, where the reversed austenite is displayed in red, and the matrix is defaulted in white. It can be seen that the reversed austenite locates mainly on prior austenite grain boundaries or between martensite laths; and with increasing $\mathrm{Mn}$ content in steels, higher amount of reversed austenite disperses in the matrix, which is consistent with $\mathrm{XRD}$ results. When the Mn content is $0.13 \%$, an appreciable quantity of reversed austenite locates at grain boundaries. However, with increasing Mn content, the amount of reversed austenite at grain boundaries gradually decreased. Such reduction may lead to a decrease in ability of grain boundary to restrain crack propagation, resulting in toughness decreasing. In addition, it can also be observed that distribution of reversed austenite is sensitive to $\mathrm{Mn}$ content variation, even the Mn content at a relatively low level.

\subsection{Effect of Mn Contents on Mechanical Properties}

Figure 8 shows the low-temperature tensile properties of the specimens containing different Mn contents. As Mn content increases, both yield strength and tensile strength increase slightly, while the elongation decreases continuously. Compared with Steel C, Steel A has a lower strength but a higher ductility. As Mn content increased, more Mn atoms solubilized into matrix and solid solution strengthening effect was enhanced, which would improve the strength of matrix. On the other hand, with increasing Mn content, more reversed austenite with lower stability would be produced, and they would transform to untempered martensite at cryogenic environment, as shown in Fig. 6. Then more dislocation would form, leading to an increase in strength. In brief, the increase in strength was ascribed to combined strengthening of solid solution strengthening and higher density of dislocations. The decrease in elongation may be related to increasing untempered martensite and the high density of dislocations. Although the elongation decreased with increasing Mn contents, the values of all specimens were still above $20 \%$, showing good ductility.

Figure 9 shows the low-temperature Charpy impact test results as a function of $\mathrm{Mn}$ contents. The cryogenic toughness decreases obviously as Mn content increases; Steel A shows the most excellent toughness at low temperature among the three. Figure 10 shows the SEM fractographic images of the impact specimens with different $\mathrm{Mn}$ contents. High amounts of tear ridges and ductile dimples are presented on the fracture surfaces of Steel A and B (Fig. 10a and b), showing a great resistance to crack 

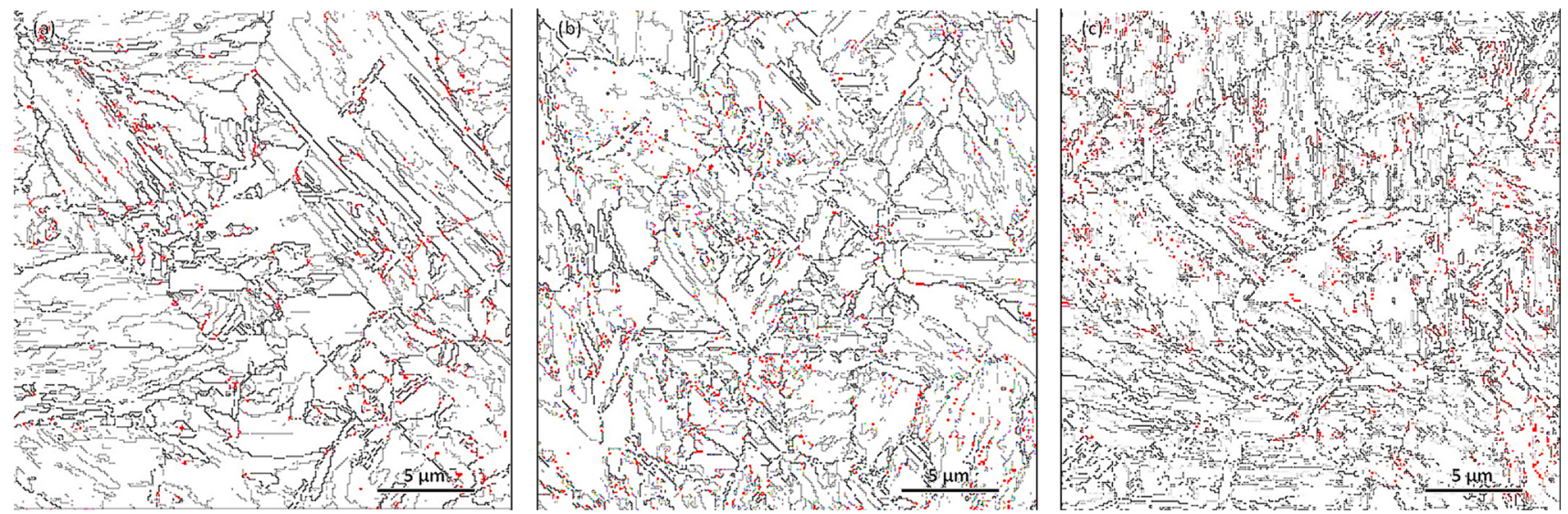

Fig. 7 Distribution of reversed austenite in the martrix measured by EBSD: a $0.13 \% \mathrm{Mn}, \mathbf{b} 0.21 \% \mathrm{Mn}$, c $0.36 \% \mathrm{Mn}$

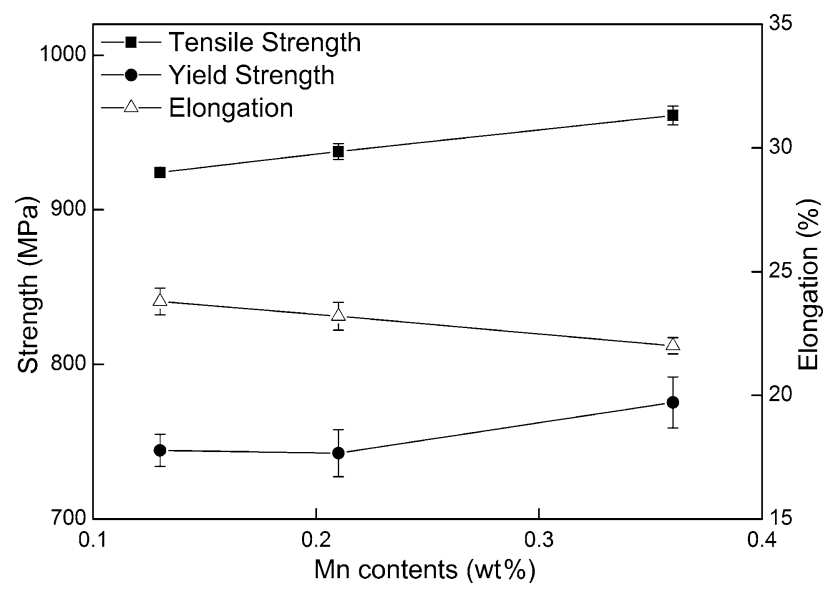

Fig. 8 Cryogenic tensile properties of specimens as a function of Mn contents

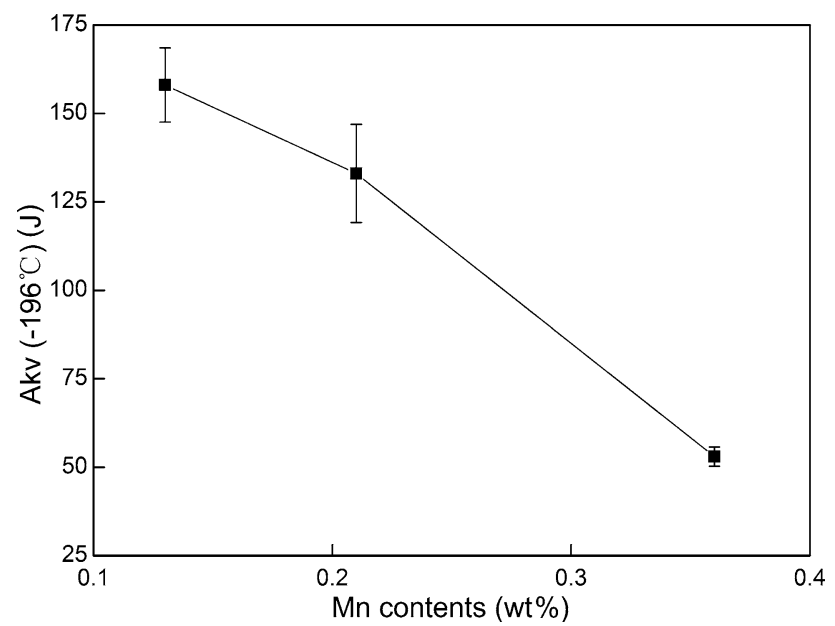

Fig. 9 Cryogenic toughness of specimens as a function of $\mathrm{Mn}$ contents

propagation and corresponding to their high values of lowtemperature impact toughness, while the dominant fracture surface is quasi-cleavage in Steel C (Fig. 10c), and there are more river pattern characteristic of cleavages on fracture surface, coinciding with its poorer impact toughness.

The variation in impact toughness value is related to the stability of the reversed austenite. As shown in Fig. 6, the stability of the reversed austenite has been reduced with increasing Mn content, as a result, more reversed austenite with good toughness would transform to untempered martensite at low temperature. That could be part of the reason why the cryogenic toughness of Steel C is relatively lower. Moreover, the change of reversed austenite distribution may also have some effect on cryogenic toughness of steels. In Fig. 7, it can be seen that the number of reversed austenite at grain boundaries declined with increasing Mn content. It is shown previously that Mn can be enriched in reversed austenite during heat treatment, i.e., reversed austenite can purify adjacent region by absorbing $\mathrm{Mn}$. Prior austenite grain boundaries can carry more microsegregation of alloying elements, such as $\mathrm{Mn}$, than laths of martensite [20]; such microsegregation on grain boundaries can reduce the resistance of crack propagation at low temperatures [21-23]. If reversed austenite formed at grain boundaries, it would absorb Mn from boundaries and, as soft phase, restrain crack propagation, resulting in improvement of toughness.

\section{Conclusion}

The effect of Mn content on the microstructure and cryogenic mechanical properties of a 7\% Ni steel was investigated within the Mn content range from $0.13 \%$ to $0.36 \%$. The size of the prior austenite grain did not change a lot as Mn content increased. Film-like reversed austenite, having high stability, was found mainly in the specimens with lower Mn content, while, in the specimen with the highest $\mathrm{Mn}$ content, the function of $\mathrm{Mn}$ was not so much to stabilize reversed austenite. With increasing Mn content, the 

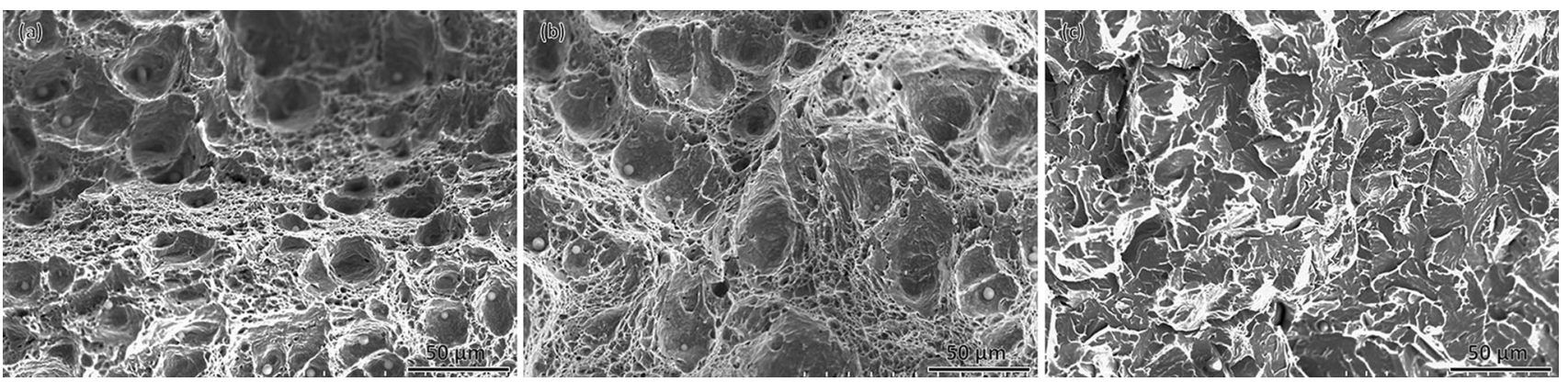

Fig. 10 Fracture morphologies of impact specimens consisted of different Mn contents: a $0.13 \% \mathrm{Mn}, \mathbf{b} 0.21 \% \mathrm{Mn}, \mathbf{c} 0.36 \% \mathrm{Mn}$

amount of reversed austenite at grain boundaries gradually decreased. The variable Mn content has a significant effect on cryogenic toughness, but not as much on cryogenic tensile strength or yield strength. An excellent combination of cryogenic tensile and impact properties was obtained when $\mathrm{Mn}$ content was $0.13 \%$. In terms of cryogenic mechanical properties, $7 \% \mathrm{Ni}$ steel has great potential to be a substitution for conventional $9 \% \mathrm{Ni}$ steel used for LNG projects or other similar applications.

Acknowledgement This work was financially supported by Wuhan Iron and Steel (Group) Corp.

\section{References}

[1] K.J. Kim, L.H. Schwartz, Mater. Sci. Eng. A 33, 5 (1978)

[2] C.K. Syn, S.G. Jin, J.W. Morris, Metall. Trans. A 7, 1827 (1976)

[3] M. Yamashita, D. Knowels, M. Mitsumoto, T. Kawabata, Development of 7\% Ni-TMCP steel plate for LNG storage tanks, in: the Asme Pressure Vessels and Piping Conference, New York, 17-21 July, 2011

[4] R.J. Song, D. Ponge, D. Raabe, ISIJ Int. 45, 1721 (2005)

[5] C.Y. Chao, C.H. Liu, Mater. Trans. 43, 2635 (2002)

[6] H.M. Deng, C.Y. Chung, J.H. Zhang, S.C. Chen, Scr. Mater. 44, $87(2001)$

[7] J.Y. Park, Y.S. Ahn, Acta Metall. Sin. (Engl. Lett.) 1, 32 (2015)
[8] J.I. Kim, C.K. Syn, J.W. Morris, Metall. Trans. A 14, 93 (1983)

[9] M. Wang, Z.L. Xie, C.G. Li, Z.Y. Liu, The development of Nicontaining cryogenic steels and their industrial manufacturing, in: Energy Materials Conference, Xi' an Shaanxi Province, 4-6 November, 2014

[10] Y.H. Yang, Q.W. Cai, H.B. Wu, H. Wang, Acta Metall. Sin. 45, 270 (2009). (in Chinese)

[11] M. Lei, Y.Y. Guo, Acta Metall. Sin. (Engl. Lett.) 4, 244 (1989)

[12] J. Chiang, J.D. Boyd, A.K. Pilkey, Mater. Sci. Eng. A 638, 132 (2015)

[13] Y.K. Lee, H.C. Shin, Y.C. Jang, S.H. Kim, C.S. Choi, Scr. Mater. 47, 805 (2002)

[14] S. Morito, K. Ohishi, K. Hono, T. Ohba, ISIJ Int. 51, 1200 (2011)

[15] B. Fultz, J.I. Kim, Y.H. Kim, J.W. Morris, Metall. Trans. A 17, 967 (1986)

[16] E.D. Moor, D.K. Matlock, J.G. Speer, M.J. Merwin, Scr. Mater. 64, 185 (2011)

[17] Y.Y. Song, J.P. Cui, L.J. Rong, J. Mater. Sci. Technol. 32, 189 (2016)

[18] M. Wang, Z. Liu, C.G. Li, Acta Metall. Sin. (Engl. Lett.) 30, 238 (2017)

[19] V. Raghavan, Metall. Mater. Trans. A 26, 237 (1995)

[20] O. Dmitrieva, D. Ponge, G. Inden, J. Millan, P. Choi, J. Sietsma, D. Raabe, Acta Mater. 59, 364 (2011)

[21] M. Kuzmina, D. Ponge, D. Raabe, Acta Mater. 86, 182 (2015)

[22] J. Han, A.K. Silva, D. Ponge, D. Raabe, S.M. Lee, Y.K. Lee, S.I. Lee, B. Hwang, Acta Mater. 122, 199 (2017)

[23] N.H. Heo, J.W. Nam, Y.U. Heo, S.J. Kim, Acta Mater. 61, 4022 (2013) 